\title{
Program to Diagnose Probability of Aspiration Pneumonia in Patients with Ischemic Stroke
}

\author{
Gisele Pinto ${ }^{1}$ Viviane Zétola ${ }^{2}$ Marcos Lange ${ }^{1} \quad$ Guilherme Gomes $^{3}$ Maria Cristina Nunes ${ }^{1}$ \\ Gisela Hirata ${ }^{4}$ Hellen Nataly Lagos-Guimarães ${ }^{1}$ \\ ${ }^{1}$ Department of Internal Medicine, Universidade Federal do Paraná \\ (HC-UFPR), Curitiba, Brazil \\ 2 Department of Internal Medicine, Universidade Federal de São Paulo \\ (USP), São Paulo, Brazil \\ 3 Department of Gastroenterology and Endoscopy, Universidade \\ Federal do Paraná (HC-UFPR), Curitiba, Brazil \\ ${ }^{4}$ Department of Communication Disorders, Universidade Tuiuti do \\ Paraná, Curitiba, Brazil \\ Int Arch Otorhinolaryngol 2014;18:244-248. \\ Address for correspondence Gisele Pinto, MSc, Gisele Santana Pinto- \\ Fonoaudióloga, Rua Palmeiras 18, Curitiba 80620110, Brazil \\ (e-mail: gi4040@gmail.com).
}

\begin{abstract}
Keywords

- stroke

- swallowing disorders

- pneumonia

Introduction Stroke is a major cause of death and disability worldwide, with a strong economic and social impact. Approximately $40 \%$ of patients show motor, language, and swallowing disorders after stroke.

Objective To evaluate the use of software to infer the probability of pneumonia in patients with ischemic stroke.

Methods Prospective and cross-sectional study conducted in a university hospital from March 2010 to August 2012. After confirmation of ischemic stroke by computed axial tomography, a clinical and flexible endoscopic evaluation of swallowing was performed within 72 hours of onset of symptoms. All patients received speech therapy poststroke, and the data were subsequently analyzed by the software. The patients were given medical treatment and speech therapy for 3 months.

Results The study examined 52 patients with a mean age of $62.05 \pm 13.88$ years, with $23(44.2 \%)$ women. Of the 52 patients, only $3(5.7 \%)$ had a probability of pneumonia between 80 and $100 \%$ as identified by the software. Of all patients, $32(61.7 \%)$ had pneumonia probability between 0 and 19\%, 5 (9.5\%) between 20 and 49\%, 3 (5.8\%) between 50 and $79 \%$, and $12(23.0 \%)$ between 80 and $100 \%$.

Conclusion The computer program indicates the probability of patient having aspiration pneumonia after ischemic stroke.
\end{abstract}

\section{Introduction}

Stroke is a major cause of death and disability worldwide, with a strong economic and social impact. Approximately $40 \%$ of patients show motor, language, and swallowing disorders. ${ }^{1}$

Stroke causes neurogenic oropharyngeal dysphagia (NOD) that, besides limiting food intake, carries a greater risk of malnutrition and tracheal aspiration and triples the incidence

received

September 12, 2013

accepted

March 11, 2014

published online

May 15, 2014
DOI http://dx.doi.org/ 10.1055/s-0034-1374646. ISSN $1809-9777$. of aspiration pneumonia. ${ }^{2-6}$ This higher risk is due to several factors, such as possibility of silent aspiration (without cough reflex) or microaspiration; motor dysfunction of the pharynx; delayed swallow initiation; presence of pharyngeal residues at epiglottic valleculae, pyriform sinuses, and/or posterior wall of the pharynx; and impairment of the laryngeal closure mechanism. The detection of such risks, in many situations, may require an alternative route for nutrition and hydration. ${ }^{7}$
Copyright $\odot 2014$ by Thieme Publicações License terms Ltda, Rio de Janeiro, Brazil

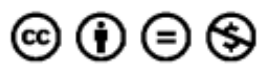


NOD occurs in $\sim 25$ to $90 \%$ of strokes, ${ }^{8-10}$ similar to the acute phase, when $45 \%$ of patients have swallowing disorders, often with tracheal aspiration. ${ }^{11}$

Tracheal aspiration is defined as the passage of saliva, fluid, or food in the subglottic region below the vocal folds. ${ }^{12,13}$ It is estimated that $50 \%$ of patients with tracheal aspiration will develop aspiration pneumonia. ${ }^{14}$

Attempting to help physicians better manage dysphagia after stroke, this study used a computer program, Nética Shell (Norsys, Vancouver, Canada), ${ }^{15}$ which uses Bayesian networks as a tool and shows results in a probabilistic form. Thus, the aim of this research is to evaluate the use of software to infer the probability of pneumonia in patients with ischemic stroke.

\section{Methods}

This was a prospective and cross-sectional study of 52 patients after ischemic stroke who were examined from March 2010 to August 2012, with 23 (44.2\%) women and 29 (55.8\%) men, with mean age of $62.05 \pm 13.88$ years. Patients were recruited in the emergency room at a university hospital in Curitiba and evaluated by a neurologist of the Neurology Department from the same institution. The diagnosis of ischemic stroke was confirmed clinically and by computed axial tomography.

The study included patients of both genders 18 years of age and older who had ischemic stroke according to clinical assessment and imaging study, confirmed by a neurologist, and who underwent clinical and instrumental evaluations of swallowing within the first 72 hours of onset of symptoms of ischemic stroke. The exclusion criteria were patients with a prior history of head and neck surgery, patients with structural abnormalities of oropharynx and larynx, those with a lowered level of consciousness with score less than 10 on the Glasgow Coma Scale, ${ }^{16}$ those clinically unstable, and patients who refused to sign the informed consent form.

The research consisted of two phases performed on the same day using clinical and flexible endoscopic evaluation of swallowing (FEES), ${ }^{17,18}$ with protocols used by the institution. During clinical swallow evaluation, the patient remained seated in reach of a cup, tablespoon, plastic syringe, and straw. The patient was then offered $5 \mathrm{~mL}, 10 \mathrm{~mL}$, and free sip of each food consistency following American Dietetic Association standard without interruption between them. ${ }^{19}$ Then the Functional Oral Intake Scale (FOIS) was administered. ${ }^{18}$

For FEES, ${ }^{17}$ the consistencies offered were similar to those used in the preceding phase, but with the addition of aniline blue dye to contrast with pink mucosa. During FEES, ${ }^{17}$ patients were offered the same sequence of swallows as in the clinical swallow evaluation. In the presence of swallowing difficulty, laryngeal penetration, or tracheal aspiration, consistencies began to be arranged progressively or the examination stopped. The test was discontinued if the patient showed nausea, vomiting, or any clinical instability.

The data collected during the test included laryngeal sensitivity, presence of premature spillage, pharyngeal residue (posterior pharyngeal wall, epiglottic valleculae, pyriform sinuses), pharyngeal clearance (after three swallows),

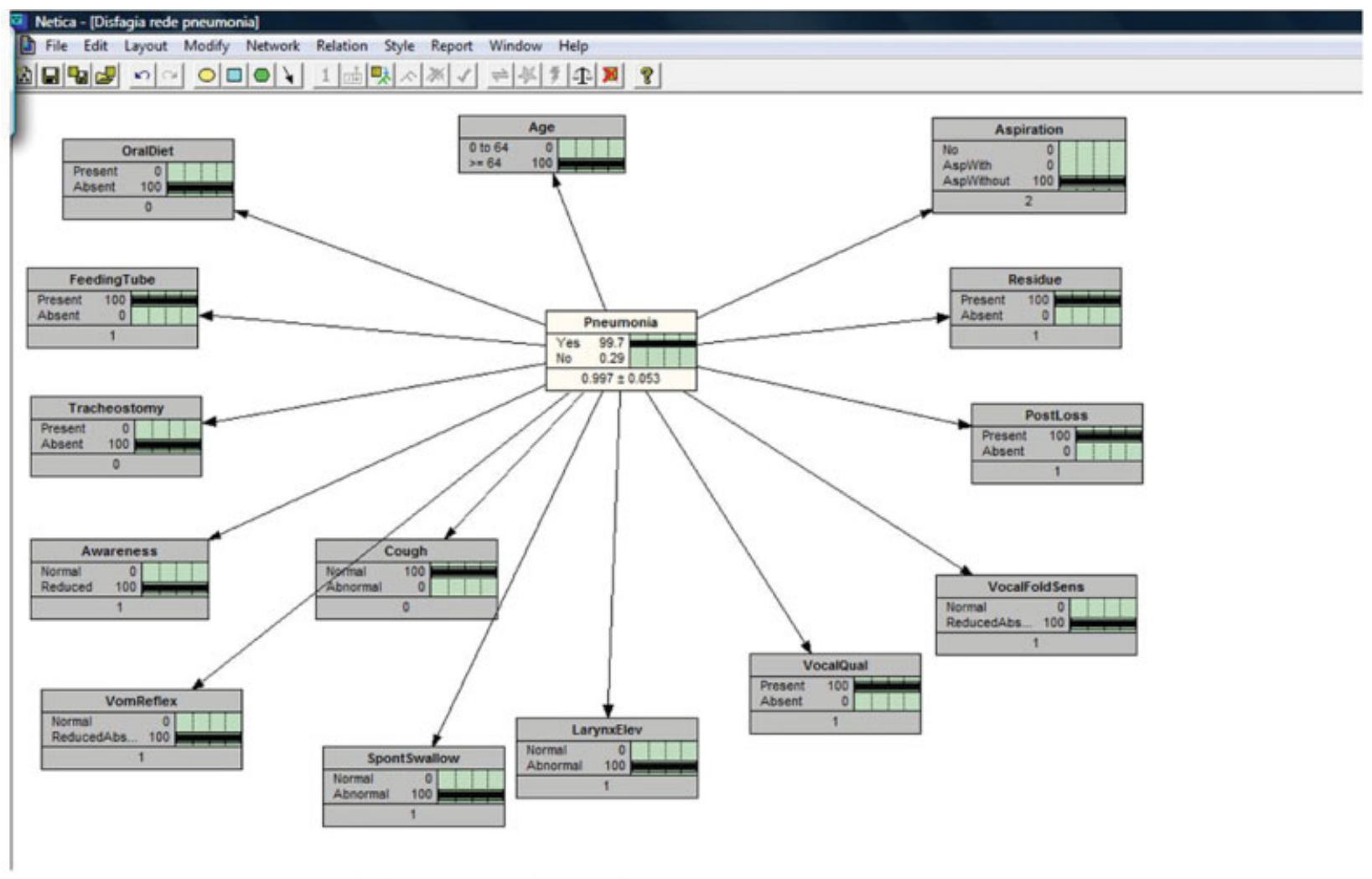

Fig. 1 Bayesian model (Gomes $\left.{ }^{21}\right)$. 
Table 1 Comparison of clinical and instrumental swallow evaluations for tracheal aspiration

\begin{tabular}{|l|l|l|l|}
\hline \multirow{2}{*}{ Tracheal aspiration } & \multicolumn{2}{|c|}{ Evaluations } \\
\cline { 2 - 4 } & Clinical & FEES \\
\hline Absent & $30(57.5 \%)$ & $34(65.4 \%)$ & 0.4201 \\
\hline Present & $22(42.5 \%)$ & $18(34.6 \%)$ & $52(100.0 \%)$ \\
\hline Total & $52(100.0 \%)$ & \\
\hline
\end{tabular}

Abbreviation: FEES, flexible endoscopic evaluation of swallowing.

and laryngeal penetration or tracheal aspiration (with or no cough reflex). The Severity Scale for Dysphagia-Penetration Aspiration Scale was administered. ${ }^{20}$

Based on the findings of clinical and instrumental assessments (FEES), ${ }^{17}$ speech therapy guidance was conducted for the patient, caregiver, and/or family.

This research used the safe mode of Bayesian network Nética Shell (Norsys, Vancouver, Canada), ${ }^{15}$ available on the Internet without charge, and the variables were created based on a previous study. ${ }^{21}$ The following findings were used as variables: clinical swallow evaluation (oral diet, tube feeding, tracheostomy, level of consciousness, gag reflex, spontaneous swallow, larynx elevation, wet voice, and voluntary cough) and FEES (laryngeal sensitivity, premature spillage, pharyngeal residue and tracheal aspiration). Thereafter, the Bayesian network was used with the findings of phases 1 and 2 (-Fig. 1) to investigate the probability of the patient developing aspiration pneumonia. Results were then divided into groups by percentage.

All patients were followed by the author and the attending physician of the patient during the hospitalization period and fortnightly for 3 months. ${ }^{22}$

Statistical analysis was performed using descriptive methods, chi-square and difference in proportions tests, with a significance level of 0.05 (5\%).

The study was approved by the Ethics Committee in Research of HC-UFPR under the number 2098.265/2009-11.

\section{Results}

Among the 52 patients, in the clinical swallow evaluation, 30 (57.5\%) showed no clinical signs of tracheal aspiration such as coughing, wet voice, and dyspnea, ${ }^{23}$ and in instrumental evaluation FEES, ${ }^{17} 34$ (65.4\%) showed no tracheal aspiration. There was no significant difference between the clinical swallow evaluation and FEES for the presence of tracheal aspiration $(p=0.4201),{ }^{17}$ as shown in - Table 1 .

Of the 18 patients (34.6\%) who had aspirated food consistencies during the examination, 14 patients $(66.6 \%)$ had tracheal aspiration of pudding consistency, 12 (57.1\%) of honey consistency, 13 (61.9\%) of nectar consistency, and 17 (80.9\%) of liquid consistency.

Regarding FOIS, ${ }^{24} 13$ (25.0\%) of the patients were at level 1 (nothing by mouth), 1 (1.7\%) patient was at level 2 (tubedependent with minimal attempts of food or liquid), 1 (1.7\%) patient was at level 3 (tube-dependent with consistent oral intake of food or liquid), 2 (4.0\%) patients were at level 4 (total oral diet of a single consistency), 5 (9.5\%) patients were at level 5 (total oral diet with multiple consistencies, but requiring special preparation or compensations), 2 (4.0\%) patients were at level 6 (total oral diet with multiple consistencies without special preparation, but with specific food limitations), and 28 (53.9\%) patients were at level 7 (total oral diet with no restrictions), as shown in - Table 2.

The Rosenbeck Scale ${ }^{20}$ showed no significant relationship between the scale and the presence or absence of pneumonia ( $p=0.2293$; - Table 3).

To allow the difference in proportions test, groups were considered in two categories: 0 to $49 \%$ and 50 to $100 \%$. Thus, difference in proportions test, with level of significance of 0.05 , resulted in $p<0.001$, that is, the proportion of patients in category 0 to $49 \%$ was significantly higher than in the category of 50 to $100 \%$ (- Table 4).

- Table 5 demonstrates the presence and absence of aspiration pneumonia within the group of patients with odds $>80 \%$ of having aspiration pneumonia and software variables. In the 3-month follow-up, only three patients had aspiration pneumonia; - Table 6 shows the outcome shown since the stroke.

\section{Discussion}

The present study implemented software to assess the probability of aspiration pneumonia in patients with acute ischemic stroke. It is not noted in the literature that any software can predict aspiration pneumonia in this population.

Studies have shown that NOD with risk of tracheal aspiration is present in up to half of patients after acute ischemic stroke. ${ }^{9,10,25}$ This finding is similar to the one obtained in the

Table 2 Distribution of patients in FOIS scale

\begin{tabular}{|l|l|}
\hline FOIS & Number of patients \\
\hline 1 & $13(25.0 \%)$ \\
\hline 2 & $1(1.7 \%)$ \\
\hline 3 & $1(1.7 \%)$ \\
\hline 4 & $2(4.0 \%)$ \\
\hline 5 & $5(9.5 \%)$ \\
\hline 6 & $2(4.0 \%)$ \\
\hline 7 & $28(53.9 \%)$ \\
\hline Total & $52(100.0 \%)$ \\
\hline
\end{tabular}

Abbreviation: FOIS, Functional Oral Intake Scale. 
Table 3 Relation between Rosenbek scale and aspiration pneumonia

\begin{tabular}{|c|c|c|c|c|c|c|c|c|c|}
\hline \multirow[t]{2}{*}{ Aspiration pneumonia } & \multicolumn{8}{|c|}{ Rosenbek scale } & \multirow[t]{2}{*}{$p$} \\
\hline & 1 & 2 & 3 & 4 & 5 & 6 & 7 & 8 & \\
\hline Present & 0 & 0 & 1 & 0 & 0 & 0 & 1 & 1 & \multirow[t]{2}{*}{0.2293} \\
\hline Absent & 30 & 1 & 1 & 1 & 0 & 0 & 4 & 12 & \\
\hline
\end{tabular}

present study, in which 22 (42.5\%) had oropharyngeal dysphagia in clinical swallow evaluation and 18 (34.6\%) in the instrumental evaluation. The difference in values between assessments is probably due to the fact that in the clinical swallow evaluation, some patients showed signs of tracheal aspiration such as coughing, wet voice, and dyspnea, ${ }^{23}$ which was not confirmed in the instrumental evaluation.

Importantly, often the clinical swallow evaluation is used to determine the next procedure with the patient in the acute

Table 4 Number of patients by percentage groups of probability of pneumonia aspiration

\begin{tabular}{|c|c|c|}
\hline \multicolumn{2}{|l|}{ Software } & \multirow[t]{2}{*}{$p$} \\
\hline $\begin{array}{l}\text { Groups by \% probability } \\
\text { of pneumonia }\end{array}$ & $\begin{array}{l}\text { Number of } \\
\text { patients }\end{array}$ & \\
\hline $0-19 \%$ & 32 (61.7\%) & \\
\hline $20-49 \%$ & 5 (9.5\%) & \\
\hline $50-79 \%$ & $3(5.7 \%)$ & $<0.001$ \\
\hline $80-100 \%$ & $12(23.1 \%)$ & \\
\hline Total & $52(100.0 \%)$ & \\
\hline
\end{tabular}

Table 5 Relation between aspiration pneumonia and patients with probability $>80 \%$ for pneumonia

\begin{tabular}{|l|l|}
\hline Pneumonia & Probability $\mathbf{8 0 - 1 0 0 \%}$ \\
\hline Present & $3(25.0 \%)$ \\
\hline Absent & $9(75.0 \%)$ \\
\hline Total & $12(100.0 \%)$ \\
\hline
\end{tabular}

phase of ischemic stroke-that is, if oral diet is or not safe for the patient. ${ }^{18,26}$ Some authors recommend a clinical swallow evaluation initially followed by an instrumental evaluation as a complementary test. ${ }^{26}$ In this study, all patients also submitted to the instrumental assessment, and the prevalence of tracheal aspiration was tested in liquid consistency. A recent study indicated that food in a liquid consistency is more likely to induce laryngeal penetration and that increased viscosity of food reduces the possibility of tracheal aspiration. $^{27,28}$

After the instrumental evaluation, patients were classified by the Severity Scale ${ }^{20}$; nothing was found in the literature correlating the scale with aspiration pneumonia. Nevertheless, in our study the three patients with aspiration pneumonia scored 3, 7, and 8 in the Rosenbeck Scale, ${ }^{20}$ resulting in death, agreeing with the authors that patients with tracheal aspiration can have aspiration pneumonia leading to morbidity and mortality of patients. 9,29

Our goal was to introduce clinical and instrumental swallow evaluation data in the software using the same variables present in a previous study. ${ }^{21}$ After analysis, the probability of each patient to develop aspiration pneumonia was assessed in percentages. It is noteworthy that the small number of cases of aspiration pneumonia in this study do not invalidate the variables used in the software, as they are consistent with aspiration pneumonia.

It is also important to mention that all patients, including the caregiver and the family, received speech therapy guidelines regarding posture, proper use of dental prosthesis, speed during feeding, amount of food to be chewed, preparation of bolus, food consistency, and head posture to prevent tracheal aspiration and consequently the nondevelopment of pneumonia. These positive results in our study are similar to other studies that show a reduction in clinical complications

Table 6 Distribution of the outcome of three patients stricken by pneumonia

\begin{tabular}{|l|l|l|l|l|l|l|l|}
\hline$n$ & Gender & Age $(\mathrm{y})$ & FOIS & $\begin{array}{l}\text { Rosenbek } \\
\text { scale }\end{array}$ & FEES & Software \% & Upshot \\
\hline 1 & F & 86 & 7 & 3 & Laryngeal penetration & 85.20 & $\begin{array}{l}\text { Decreased consciousness, } \\
\text { pneumonia and death }\end{array}$ \\
\hline 2 & M & 83 & 4 & 7 & Tracheal aspiration & 98.41 & Sepsis, pneumonia and death \\
\hline 3 & M & 74 & 1 & 8 & Tracheal aspiration & 99.50 & $\begin{array}{l}\text { Decreased consciousness, } \\
\text { pneumonia, and death }\end{array}$ \\
\hline
\end{tabular}

Abbreviations: FEES, flexible endoscopic evaluation of swallowing; FOIS, Functional Oral Intake Scale. 
with preventive and therapeutic measures in acute stroke patients. $^{26}$

Teamwork of a multidisciplinary unit with a speech therapist ensures patient safety during feeding and avoids the risks of tracheal aspiration.

\section{Conclusion}

The software is indicative of the probability of the patient having aspiration pneumonia, but the sample was not sufficient. A larger sample size is required, along with continuity of this study.

\section{References}

1 Pires SL, Gagliardi RJ, Gorzoni ML. Estudo das freqüências dos principais fatores de risco para acidente vascular cerebral isquêmico em idosos. Arq Neuropsiquiatr 2004;62(3B):844-851

2 Barros AFF, Fábio SRC, Furkim AM. Correlação entre os achados clínicos da deglutição e os achados da tomografia computadorizada de crânio em pacientes com acidente vascular cerebral isquêmico na fase aguda da doença. Arq Neuropsiquiatr 2006; 64(4):1009-1014

3 ASHA. American Speech-Language-Hearing Association. Model Medical Review Guidelines for Dysphagia Services. 2004 Revision to DynCorp 2001 FTRP by ASHA. Available at: http://www. asha.org/uploadFiles/practice/reimbursement/medicare/DynCorpDysphHCEC.pdf

4 Logemann J. Oropharyngeal dysphagia and nutritional management. Curr Opin Clin Nutr Metab Care 2007;10(1):611-614

5 Abdulmassih EMS, Macedo-Filho ED, Santos RS, Jurkievicz A. Evolution of patients with oropharyngeal dysphagia in hospital enviroment. Int Arch Otorhinolaryngol 2009;13(1):55-62

6 Baroni AFFB, Fábio SRC, Dantas RO. Risk factors for swallowing dysfunction in stroke patients. Arq Gastroenterol 2012;49(2): $118-124$

7 Silva F. Acidente vascular cerebral isquêmico. Prevenção: Aspectos atuais. É preciso agir. Med Intern 2004;11(2):104-111

8 Nunes MCA, Jurkievicz AL, Santos RS, et al. Correlation between brain injury and dysphagia in adult patients with stroke. Int Arch Otorhinolaryngol 2012;16(3):313-321

9 Schelp AO, Cola PC, Gatto AR, Silva RG, Carvalho LR. Incidência de disfagia orofaríngea após acidente vascular encefálico em hospital público de referência. Arq Neuropsiquiatr 2004;62(2B):503-506

10 Remesso GC, Fukujima MM, Chiappetta ALML, et al. Swallowing disorders after ischemic stroke. Arq Neuropsiquiatr 2011;69(5): 785-789

11 Furkim AM. O gerenciamento fonoaudiológico das disfagias orofaríngeas neurogênicas. In: Furkim AM, Santini CS, eds. Disfagias Orofaríngeas. 2nd ed. São Paulo, Brazil: Pró-fono; 2004:229-258
12 Irwin RS. Aspiration. In: Irwin RS, Cerra FB, Rippe JM, eds. Irwin and Rippe's Intensive Care Medicine. Philadelphia, PA: LippincottRaven; 1999:685-692

13 Ramsey D, Smithard D, Kalra L. Silent aspiration: what do we know? Dysphagia 2005;20(3):218-225

14 AHCPR. Agency for Health Care Policy and Research. Diagnosis and Treatment of Swallowing Disorders (Dysphagia). Acute-Care Stroke Patients Summary. Philadelphia, PA: Evidence Report/ Technology Assessment; 1999

15 Norsys. Products. Available at: http://www.norsys.com. Accessed Sep 10, 2013

16 Hudak C, Gallo B. Cuidados intensivos de enfermagem: uma abordagem holística. 6.nd. Rio de Janeiro, Brazil: Guanabara Koogan; 1997

17 Langmore SE, Schatz K, Olsen N. Fiberoptic endoscopic examination of swallowing safety: a new procedure. Dysphagia 1988;2(4): 216-219

18 Prosiegel M, Riecker A, Weinert M, et al. [Management of dysphagic patients with acute stroke]. Nervenarzt 2012;83(12): 1590-1599

19 Ayoob KT, Duyff RL, Quagliani D. American Dietetic Association. Food and nutrition misinformation: position of ADA. J Am Diet Assoc 2002;102(1):260-266

20 Rosenbek JC, Robbins JA, Roecker EB, Coyle JL, Wood JL. A penetration-aspiration scale. Dysphagia 1996;11(2):93-98

21 Gomes GF. Identificação de fatores preditivos de pneumonia aspirativa em pacientes hospitalizados com doença cerebrovascular complicada por disfagia orofaríngea [Tese de Doutorado]. Curitiba, Brazil: Setor de Ciências da Saúde, da Universidade do Paraná; 2001

22 Howick J. Levels of evidence and grades of recommendation. 2009. Available at:http://www.cebm.net/?o=1025. Accessed Sep 10, 2013

23 Marik PE. Aspiration pneumonitis and aspiration pneumonia. N Engl J Med 2001;344(9):665-671

24 Crary MA, Mann GD, Groher ME. Initial psychometric assessment of a functional oral intake scale for dysphagia in stroke patients. Arch Phys Med Rehabil 2005;86(8):1516-1520

25 Perry L, Love CP. Screening for dysphagia and aspiration in acute stroke: a systematic review. Dysphagia 2001;16(1):7-18

26 Marques CH, André C, Rosso ALZ. Disfagia no AVE agudo: Revisão sistemática sobre métodos de avaliação. Acta Fisiatr 2008;15(2): 106-110

27 Pires EC, Sassi FC, Mangelli LD, Limongi SCO, Andrade CRF. Alimentos na consistência liquida e deglutição uma Revisão crítica da literatura. Rev Soc Bras Fonoaudiol 2012;17(4):482-488

28 Clavé P, De Kraa M, Areola V, Girvent M, Farre R. Serra-Prat. The effect of bolus on swallowing function in neurogenic dysphagia. Aliment Pharmacol Ther 2006;24(9):1385-1394

29 Wilson RD. Mortality and cost of pneumonia after stroke for different risk groups. J Stroke Cerebrovasc Dis 2012;21(1):61-67 